\title{
Pricing Strategy of Cruise Companies
}

\author{
Huashan Tan ${ }^{1,}$, Yang Yang ${ }^{2, b}$ \\ ${ }^{1}$ School of Computer and Information Science, Chongqing Normal University, Chongqing, China \\ ${ }^{2}$ School of Economics \& Management, Chongqing Normal University, Chongqing, China \\ a6510388@qq.com, blilyangyy@163.com
}

Keywords: product pricing; oligopoly; game theory; Nash equilibrium.

\begin{abstract}
This paper researches the product pricing problems of cruise companies in the oligopoly market, discusses a cooperative game model and a non cooperative game model, and gives equilibrium results of pricing game between two oligopoly companies by analyzing the solution of models.
\end{abstract}

\section{Introduction}

The price is the most complex and the most sensitive factor of the market economy. Any product and services have pricing problems. It tries to make the company's benefit maximization by management decision on price. But enterprise pricing behavior will show different characteristics according to different market structure. In fact, China Three Gorges cruise tourism market belongs to oligopoly market structure [1]. The cruise company's pricing decision will not only affect the other competitor's demand, but their own demand will be also affected by the other competitors. So the managers should make decision fully considering the competition's information and strategy.

This paper uses the game theory[2-3] to research the product pricing problems of cruise companies in the oligopoly market, discusses a cooperative game model and a non cooperative game model, uses multivariate linear regression model to deduce the empirical relation between sale quantity and prices of two oligopoly companies, and gives equilibrium results of pricing game between them.

\section{The Game Model between the Same Types of Cruise Companies}

\section{The analysis of the demand model}

The demand of the commodity and the service is influenced by many factors, such as prices, consumer's income, prices of related goods, consumer preference. This paper mainly researches the relationship between the quantity demanded and the price.

Firstly, it makes a hypothesis that the quantity demanded of the Three Gorges cruise is the function about the average price which is expressed with $p$.

$q=a-b p$, In this equation, coefficient $b$ said the price elasticity of demand. Because the variable cost of cruise companies is such less than the fixed cost that we can have an assumption that the total operation cost of cruise companies is constant. A single cruise company makes decision of monopoly pricing based on the revenue maximization principle. The decision model is the equation. $\max R=p q=p(a-b p)$.

Based on this model, it is further to establish the pricing game model of cruise companies under the duopoly competition situation. If the two cruise companies have the same operation cost, the quantity demanded of each cruise company tickets depends on the average price of his own and his competitor.

To explain this, we hypothesize a connection between these factors: $\begin{aligned} & q_{1}=a_{1}-b_{1} p_{1}+c_{1} p_{2} \\ & q_{2}=a_{2}-b_{2} p_{2}+c_{2} p_{1}\end{aligned}$

In these equations, coefficient $p_{1}$ and $p_{2}$ said the each average price of cruise company tickets. The model parameters can be obtained from historical data through the statistical analysis. 


\section{A non cooperative game model}

By hypothesis, we can build the static game model on complete information. The profit function is as follows:

$$
\begin{aligned}
& R_{1}=p_{1} q_{1}=a_{1} p_{1}-b_{1} p_{1}^{2}+c_{1} p_{1} p_{2} \\
& R_{2}=p_{2} q_{2}=a_{2} p_{2}-b_{2} p_{2}^{2}+c_{2} p_{1} p_{2}
\end{aligned}
$$

By the optimization fist-order condition, the model solution is as follows:

$$
\left\{\begin{array}{l}
\frac{\partial R_{1}}{\partial P_{1}}=a_{1}-2 b_{1} p_{1}+c_{1} p_{2}=0 \\
\frac{\partial R_{2}}{\partial P_{2}}=a_{2}-2 b_{2} p_{2}+c_{2} p_{1}=0
\end{array}\right.
$$

From it, we can get the only Nash equilibrium solution as follows:

$$
\left\{\begin{array}{l}
p_{1}=\frac{2 a_{1} b_{2}+c_{1} a_{2}}{4 b_{1} b_{2}-c_{1} c_{2}} \\
p_{2}=\frac{2 a_{2} b_{1}+c_{2} a_{1}}{4 b_{1} b_{2}-c_{1} c_{2}}
\end{array}\right.
$$

This is the game equilibrium strategy of both sides in the competition environment, also be the optimal strategy.

\section{A cooperative game model}

In order to further explain the Nash equilibrium, this paper establishes the decision making model for optimization of cooperation between two sides. It is a cooperative game model [4-5]. At this time, both sides combined to make the pricing decisions. Their target is maximization of both total profits. The optimization model is as follows:

$$
\max R=R_{1}+R_{2}
$$

By the optimization fist-order condition, the model solution is as follows:

$$
\left\{\begin{array}{l}
\frac{\partial R_{1}}{\partial P_{1}}=a_{1}-2 b_{1} p_{1}+c_{1} p_{2}+c_{2} p_{2}=0 \\
\frac{\partial R_{2}}{\partial P_{2}}=a_{2}-2 b_{2} p_{2}+c_{2} p_{1}+c_{1} p_{1}=0
\end{array}\right.
$$

From it, we can get the only Nash equilibrium solution as follows:

$$
\left\{\begin{array}{l}
p_{1}^{*}=\frac{2 a_{1} b_{2}+a_{2}\left(c_{1}+c_{2}\right)}{4 b_{1} b_{2}-\left(c_{1}+c_{2}\right)^{2}} \\
p_{2}^{*}=\frac{2 a_{2} b_{1}+a_{1}\left(c_{1}+c_{2}\right)}{4 b_{1} b_{2}-\left(c_{1}+c_{2}\right)^{2}}
\end{array}\right.
$$

Because the first-order leading minor $\left(\Delta_{1}=-2 b_{1}<0\right)$ of the Hesse matrix $\left(\left|\begin{array}{cc}-2 b_{1} & c_{1}+c_{2} \\ c_{1}+c_{2} & -2 b_{2}\end{array}\right|\right)$ is less than zero, the Hesse matrix is a negative definite matrix when the second-order leading minor $\left(\Delta_{2}=\left|\begin{array}{cc}-2 b_{1} & c_{1}+c_{2} \\ c_{1}+c_{2} & -2 b_{2}\end{array}\right|>0\right)$ is more than zero. If the objective function meets the conduction as fellows: $\Delta_{2}=4 b_{1} b_{2}-\left(c_{1}+c_{2}\right)^{2}>0$, the optimization model has the only Nash equilibrium solution.

The equilibrium solutions of the two models have the relationship as follows:

$$
\left(p_{1}, p_{2}\right)<\left(p_{1}^{*}, p_{2}^{*}\right), R\left(p_{1}, p_{2}\right)<R\left(p_{1}^{*}, p_{2}^{*}\right)
$$

We can draw a conclusion that the equilibrium price of the cooperation is higher than the price of the non cooperation, and the same to the total income. 
Further, we can obtain the enlightenment on management that the efficiency of the decision under the competition situation is lower than it under the cooperation situation. From the angle of the efficiency, both sides have the potential incentive to cooperate. It means that there is the basis for existence to form the price alliance.

\section{An Example of Model and Solution}

Now we discuss a specific example. The table below is the ticket sales data of Chongqing Yangtse River cruise company and new century cruise company in some years in an area.

Table 1. Ticket Sales Data of Two Oligarchs Cruise Companies

\begin{tabular}{|l|c|c|c|c|c|c|c|}
\hline \multicolumn{1}{|c|}{ VAR } & Apr & May & Jun & Jul & Aug & Sep & Oct \\
\hline $\begin{array}{l}\text { Ticket price of Chongqing Yangtse } \\
\text { River cruise company } \\
\text { (Measurement units per 1000) }\end{array}$ & 3.8 & 3.6 & 3.4 & 3.3 & 3.2 & 4.0 & 3.9 \\
\hline $\begin{array}{l}\text { Sales volume of Chongqing } \\
\text { Yangtse River cruise company } \\
\text { (Measurement units per 100) }\end{array}$ & 111.2 & 112 & 116.7 & 117.2 & 114.1 & 113.8 & 110.3 \\
\hline $\begin{array}{l}\text { Ticket price of Chongqing new } \\
\text { century cruise company } \\
\text { (Measurement units per 1000) }\end{array}$ & 4.2 & 4.0 & 3.9 & 3.8 & 3.5 & 4.5 & 4.3 \\
\hline $\begin{array}{l}\text { Sales volume of Chongqing new } \\
\text { century cruise company } \\
\text { (Measurement units per 100) }\end{array}$ & 94.3 & 96.1 & 96.5 & 97.4 & 103.6 & 93.5 & 92.1 \\
\hline
\end{tabular}

Using the data in Table I by the regression output results of SPSS software, it can be obtained the multivariate linear regression model of the empirical relation between sales volume and prices of the two companies as follows:

$$
\begin{aligned}
& q_{1}=128.058-31.611 p_{1}+24.663 p_{2} \\
& T=(27.799)(-5.674) \text { (4.733) } \\
& \text { Sig }=\left(\begin{array}{lll}
0.000) & (0.005) & (0.009
\end{array}\right) \\
& R=0.958 \quad R^{2}=0.917 \quad F=22.070 \\
& q_{2}=137.954-16.768 p_{2}+7.17 p_{1} \\
& T=(16.672)(-1.807) \quad(0.716) \\
& \text { Sig }=(0.000)(0.513) \quad(0.145) \\
& R=0.930 \quad R^{2}=0.866 \quad F=12.897
\end{aligned}
$$

After we get the parameters of the mutiple linear regression model, we also need to make the statistical test of the regression function furtherly. At the first, we make the $\mathrm{T}$ test for the regression coefficients of the formula (8) and (9). From the T test results we can see that prices of the two companies have the significant effect on the sales volume. Then, the $F$ test was performed on the overall significance of the regression model.

Firstly, we test the significance of the model (8). From the above data, $R^{2}=0.917, n=7, k=3$, we can calculate that $F=\frac{E S S /(k-1)}{R S S /(n-k)}=\frac{R^{2} /(k-1)}{\left(1-R^{2}\right) /(n-k)}=22.070$. We can check the critical value that is $F_{0.05}(2,4)=6.94$ when the given level of significance is $\alpha=0.05$, the first degree of freedom is $k-1=2$, and the second degree of freedom is $n-k=4$. Because that $F=22.070>F_{0.05}(2,4)=6.94$, the regression model (8) has the whole significance. 
Secondly, we test the significance of the model (9). From the above data, $R^{2}=0.866, n=7, k=3$, we can calculate that $F=\frac{E S S /(k-1)}{R S S /(n-k)}=\frac{R^{2} /(k-1)}{\left(1-R^{2}\right) /(n-k)}=12.897$. We can check the critical value that is $F_{0.05}(2,4)=6.94$ when the given level of significance is $\alpha=0.05$, the first degree of freedom is $k-1=2$, and the second degree of freedom is $n-k=4$. Because that $F=12.897>F_{0.05}(2,4)=6.94$, the regression model (9) has the whole significance.

From the $\mathrm{T}$ test results we can see that prices of the two companies have the significant effect on the sales volume. While the F test results show that the regression model has the whole significance.

Then if we put the regression coefficient into the (4), we can get the only Nash equilibrium solution $\left(p_{1}, p_{2}\right)=(3.84,4.9)$. This is the pricing strategy by which the two companies make the profit maximizing in the competitive environment. We can get the maximum profit of Chongqing Yangtse River cruise company as follows:

$$
R_{1}=p_{1} q_{1}=a_{1} p_{1}-b_{1} p_{1}^{2}+c_{1} p_{1} p_{2}=128.058 \times 3.84-31.611 \times 3.84+24.663 \times 3.84 \times 4.9=834.415
$$

And we can get the maximum profit of Chongqing new century cruise company as follows too:

$$
R_{2}=p_{2} q_{2}=a_{2} p_{2}-b_{2} p_{2}{ }^{2}+c_{2} p_{1} p_{2}=137.954 \times 4.9-16.768 \times 4.9+7.17 \times 3.84 \times 4.9=728.722
$$

If we put the regression coefficient into the (7), we can get the only Nash equilibrium solution $\left(p_{1}^{*}, p_{2}^{*}\right)=(7.16,10.76)$. This is the pricing strategy by which the two companies make the profit maximizing in the cooperative environment. Apparently, cooperation is more advantageous than competition between both sides. However, many factors hinder alliance between two companies such as competition from the other small companies, the supervision and management of the government, market segmentation etc.

\section{Conclusion}

This paper uses the game theory to discuss the product pricing decision model of the duopoly cruise companies in the competitive environment, and has carried on the contrast analysis with the cooperative situation. The model analysis on the product pricing decision of cruise companies has certain practical significance, at the same time to the industry supervision, to avoid vicious competition also has reference value.

\section{Acknowledgement}

This work was supported by the Science Technology Researching Fund of Chongqing Education Committee (KJ100623, KJ110629).

\section{References}

[1] Serguei Netesine, Robert A. Shumsky. Revenue, Management Games: Horizontal and Vertical Competition, Management Science, 51(2005) 813-831.

[2] Zheng weiying, Game theory and information economics, Shanghai people’s Publishing House, 2004.

[3] Bolton Gary E, Game theory’s role in role-playing, International Journal of Forecasting, 18(2002) 353-358.

[4] Kale P., Singh H., Perlmutter H, Learning and protection of proprietary assets in strategic alliances: Building relational capital, Journal of Strategic Management, 21(2000) 217-237.

[5] Doz Y. L., The evolution of cooperation in strategic alliances: Initial conditions or learning processes, Journal of Strategic Management, 17(1996) 55-83. 